\title{
Suitability of commercial human rheumatoid factor rapid tests for detection of rheumatoid factors in dog serum
}

\author{
C.N. Weber, J.O. Zeitz, E. Müller
}

\section{LABOKLIN GmbH \& Co. KG, 97688 Bad Kissingen}

\section{Introduction}

The diagnosis of rheumatoid arthritis may be supported by detection of serum rheumatoid factors $(R F)$, autoantibodies directed against the Fc region of $\lg G$ immunoglobulins (1).

Agglutination tests are used widespread for RF detection, amongst them haemagglutination tests based on the Waaler Rose principle which measures the capability of serum RF to agglutinate sheep erythrocytes sensitized with rabbit IgG (2,3, Fig. 1a). Additionally, serum RF cause agglutination of latex particles coated with species-specific IgG in latex agglutination tests (Fig. 1b).

Rapid agglutination tests are commercially available, time-saving, and would be useful in veterinary practice. However, it is unclear if such rapid RF tests developed for human RF detection are suitable to detect canine RF. Therefore, we examined if commercially available rapid tests for RF detection in humans are also suitable to detect RF in dog serum.

\section{Material and Methods}

\section{Sample material:}

- 12 dog sera, positive $(n=6)$ or negative $(n=6)$ in the reference test

- One human serum, positive in reference test

- Sera were used at day of arrival in the lab or after storage at $-20^{\circ} \mathrm{C}$

\section{Reference test:}

validated test routinely used at Laboklin $\mathrm{GmbH} \& \mathrm{Co}$. KG (haemagglutination test based on Waaler Rose principle; sensitivity $86 \%$, specificity $97,91 \%$ )

\section{Examined tests:}

10 commercially available rapid tests for human RF detection (Table 1)

Procedure: qualitative method according to the manufactur's guide

- 2-3 min incubation with pure sera, visual examination of agglutination (Fig. 2)

- In case of agglutination in pure sera: dilution of sera to allow differentiation of presence of RF from that of heterophilic antibodies

Table 1. Examined commerical rapid tests 1-10

\begin{tabular}{|c|c|c|c|c|c|c|c|}
\hline Kit & Principle & Name & Supplier & $\begin{array}{l}\text { Ref. } \\
\text { number }\end{array}$ & $\begin{array}{c}\text { Analytical } \\
\text { Sens., IU/ml }\end{array}$ & $\begin{array}{l}\text { Sens., } \\
\%\end{array}$ & $\begin{array}{l}\text { Spec., } \\
\%\end{array}$ \\
\hline T1 & WR & Rose Waaler & $\begin{array}{l}\text { Lorne Laboratories } \\
\text { Ltd. }\end{array}$ & $156050 \mathrm{~A}$ & 8 & 100 & 93,6 \\
\hline T2 & WR & Waaler Rose Kit & bestbion dx GmbH & 96111 & 8 & 100 & 93,6 \\
\hline T3 & WR & $\begin{array}{l}\text { NADAL® Waaler } \\
\text { Rose Test }\end{array}$ & nal von minden $\mathrm{GmbH}$ & 795017 & 8 & 100 & 93,6 \\
\hline T4 & WR & Waaler Rose & Dialab GmbH & 495055 & 8 & 100 & 93,6 \\
\hline T5 & WR & Waaler Rose & Cypress Diagnostics & 22162 & 8 & 100 & 93,6 \\
\hline T6 & WR & Waaler Rose Test & Mascia Brunelli S.p.a. & UA80255 & 8 & N.S. & N.S. \\
\hline T7 & WR & celarkit AR & Werfen GmbH & $3000-1020$ & 7 & N.S. & N.S. \\
\hline T8 & LA & rheumajet RF & Werfen GmbH & $3800-0145$ & 10 & N.S. & N.S. \\
\hline T9 & LA & RF-Latex & Cypress Diagnostics & 22112 & 8 & 100 & 100 \\
\hline T10 & LA & RF-Latex & Mascia Brunelli S.p.a. & UA80210 & 8 & 98 & 97 \\
\hline
\end{tabular}

T1-10, Rapid tests 1-10; WR, Waaler Rose principle, LA, latex agglutination principle. Sens./Spec. diagnostic sensitivity/specificity for human according to the manufacturer; N.S, not specified.

\section{Discussion and Conclusions}

None of the examined rapid latex agglutination tests was suitable for the detection of RF in dog sera. Because canine RF has low affinity for human $\operatorname{lgG}$, this result was foreseeable: the examined rapid latex agglutination tests use human IgG coated latex particles. Therefore, canine IgG coated latex particles should be used in latex agglutination tests for dogs (5).

Likewise, none of the examined rapid haemagglutination tests detected RF in dog sera, although these tests use the non species-specific Waaler Rose principle which generally works in many animal species. Time needed for antibody binding may be prolonged though; thus, the use rapid tests with haemagglutination principle for RF detection may be limited in various animal species.

In summary, none of the examined rapid agglutination tests was suitable to detect canine RF. Therefore, specialized laboratory testing for canine RF is recommended.

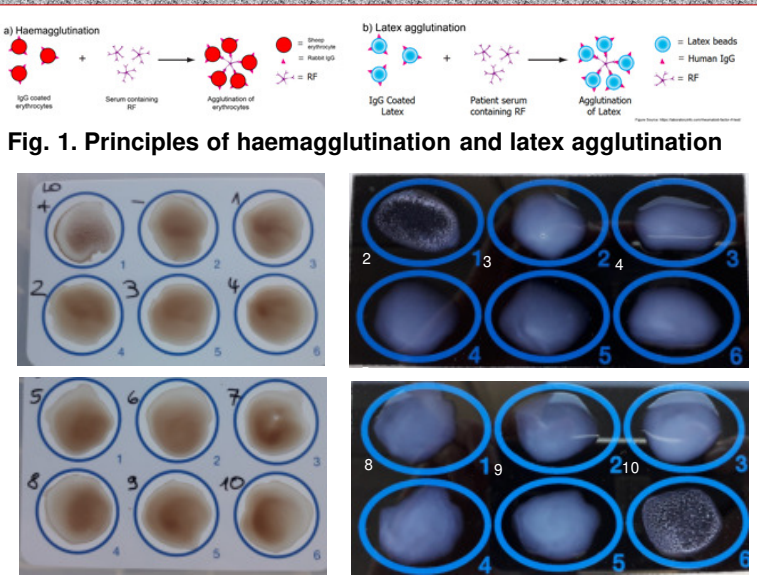

Fig. 2. Visual examination of agglutination by comparison with positive and negative control in rapid tests based on haemagglutination (left, test T1) or latex agglutination (right, test T9). +/-, positive/negative control. 1-10, sample number (see Table 2)

\section{Results}

The human serum was positive in all rapid tests (Tab. 2). However, the incubation time was prolonged to 5-8 $\mathrm{min}$ in tests based on the Waaler Rose haemagglutination to achieve clear agglutination.

The negative and positive tested dog sera were all negative in the rapid tests even after prolonged incubation times. Serum 8, which caused agglutination We we diluted 1.10. with rapid tests $1-10$ in comparison to the reference test $(R)$

\begin{tabular}{|c|c|c|c|c|c|c|c|c|c|c|c|c|c|}
\hline No. & 1 & 2 & 3 & 4 & 5 & 6 & 7 & 8 & 9 & 10 & 11 & 12 & 13 \\
\hline Sp. & D & D & D & D & D & D & D & D & $D$ & $\mathrm{H}$ & D & D & D \\
\hline $\mathrm{R}$ & + & + & - & + & - & + & - & - & + & + & + & - & - \\
\hline Titer & 1:128 & $1: 64$ & $<1.16$ & $1: 128$ & $1: 32$ & 1:64 & $<1: 16$ & $<1: 16$ & 1:64 & $1: 64$ & 1:128 & $<1: 16$ & $<1: 16$ \\
\hline T1 & - & - & - & - & - & - & - & - & - & $(+)$ & - & - & - \\
\hline T2 & - & - & - & - & - & - & - & - & - & $(+)$ & - & - & - \\
\hline T3 & - & - & - & - & - & - & - & - & - & $(+)$ & - & - & - \\
\hline T4 & - & - & - & - & - & - & - & - & - & $(+)$ & - & - & - \\
\hline T5 & - & - & - & - & - & - & - & - & - & $(+)$ & - & - & - \\
\hline T6 & - & - & - & - & - & - & - & - & - & $(+)$ & - & - & - \\
\hline T7 & - & - & - & - & - & - & - & - & - & $(+)$ & - & - & - \\
\hline T8 & - & - & - & - & - & - & - & - & - & + & - & - & - \\
\hline T9 & - & - & - & - & - & - & - & - & - & + & - & - & - \\
\hline T10 & - & - & - & - & - & - & - & - & - & + & - & - & - \\
\hline
\end{tabular}

Literature

(1) Bennet, D., Kirkham, D. (1987): J Comp. Path. 97: 541-550.

(2) Waaler, E. (1940). APMIS. 17: 172188.

(3) Rose, H.M., Ragan, C., Pearce, E., Lipman, M.O. (1948). Proc Soc Exp Biol Med. 68: 1-6.

(4) Singer, J.M., Plotz, C.M. (1956). Am. J. Med. 21: 888-892

(5) Wood, D.D., Hurvitz, A.I., Schultz, R.D. (1980): Vet. Immunol. Immunop. 1: 103111.

We thank the companies which supplied test kits free of charge or with reduced price. 